cussed and evaluated. In the light of their own research, the authors select the theory of Szasz as being most acceptable because it covers all varieties of pain. Accord. ing to this theory, pain is a consequence of the perception of a threat to the integrity of the body, where the body is considered to be an object separate from and valued by the ego. The threat may not be apparent to an outside observer and the pain is then classed as "psychogenic".

This comprehensive review, with its extensive bibliography, will not only be invaluable to those whose research activities are directed towards the study of pain, but also of great interest to many other people, including psychologist,s, psychiatrists and general practitioners.

Diana R. Haslam

\section{DEALING WITH LITERATURE}

\section{On Documentation of Scientific Literature}

By Th. P'. Loosjes. 'Translated by A. J. Dickson. Pp. ix +165 . (London: Butterworth and Co. (Publishers), Ltd., 1967.) $42 s$.

\section{The Growth of Knowledge}

Readings on Organization and Retrieval of Information. Edited by Manfred Kochen. Pp. 394. (New York and London: John Wiley and Sons, 1967.) 113s.

THE literature of documentation has proliferated in aceord with the increase in documentation services and the research funds that have been made available during the past ten yoars. In his book, Mr Loosjes has attempted to cover the whole field of documentation from the development of periodicals to the cost benefit evaluation of information systems. The result is a volume which combines brief but lucid discussion of the various aspects and techniques with a comprehensive but not over-exhaustive listing of references. Interspersed are proposals by the author as to how various difficulties might be overcome, such as the problems of bibliographical control of scientific and technical literature. For the student, this volume can be thoroughly recommonded as providing a balanced view of current practice, while many librarians and information officers could read it with profit to themselves, and would certainly find it useful as a quick reference source. How. ever, one will find only the briefest mention of any possible future developments and the book is strictly a review of the present position and of conventional techniques.

The reverse is true of the volume edited by Dr Kochen, even though he goes back to 1936 for the first paper in this collection of essays. This is the "World Encyclopaedia" by H. G. Wells, and introduces a section which includes the classic paper by Vannevar Bush, "As we may think", an extract from the Weinberg report on "Science, Government and Information", "The Universal Brain" by Watson Davis, and the paper by Van Doren, "The Idea of an Encyclopaedia" which was published in 1962. There is then a somewhat disappointing group of four papers dealing with possible libraries of the future. The following section, which eovers the background to tho present position of information retrieval, including "Networks of Scientific Papers" by de Solla Price, the exposition of Parkinson's Law, and papers by Carnap, Swets and Kochen, is possibly the most stimulating section of the book. The remaining ten papers, all published during the past decade, are chiefly concerned with the part that computers can play in overcoming the problems posed in the earlier papers.

While I might have welcomed the stimulation of an early Fairthorne in place of, for example, the account of the proposals of the Committee on Scientific and Technical Information, the selection of essays can scarcely be faulted. 'The editor has been admirably impartial; the optimistic review of the possibilities of question-answering systems by Simmons is followed by Asa Kashen's critical survey on data retricval by computer, which is strongly reminiscent of the better-known paper by Bar-Hillel. There is a factual account of MEDLARS, the largest mechanized information retrieval system which now contains more than 600,000 citations and which requires a large staff of professional indexers to deal with the annual intake of some 200,000 articles. The following paper, by Salton, Keen and Lesk, describes experiments in auto. matic information retrieval that have been carried out at Harvard and Cornell. Although the test collections in these experiments have been limited to 1,000 documents, the results provide reasonable grounds for hoping that the designers of future information services will be able to use automatic text analysis and still be able to operate at the same level of efficiency as present day systems using manual subject indexing.

While none of the essays in this volume is an original contribution, they are, with few exceptions, stimulating reading, and this volume can be recommended for anyone who wishes to study or who is concerned with the possible developments in information technology.

Cyril Creverdon

\section{INFORMATION REVIEW}

Annual Review of Information Science and Technology Vol. 2. (American Documentation Institute.) Edited by Carlos A. Cuadra. Pp. viii +484 . (New York and London: Interscience Publishers, a Division of John Wiley and Sons, 1967.) 140s.

THE second volume in this new review series certainly supports and further justifies the acclaim which greeted its predecessor. It clearly rests on a sound basis of administration with financial support from the National Science Foundation, and a competent group of reviewers who make their personal selection from an extensive biblingraphy compiled by the Systems Development Corporation.

When an inchoate spread of marginal fields and border studies begins to consolidate into a discipline in the traditional sense it is characteristic for abstracting services and annual reports of progress to begin to appear. In this case, however, definition and seope are still as debatable as ever. Broadly speaking, an attempt is made to distinguish three related areas, librarianship, information science and information technology, although they tend to overlap. In one definition quoted, information tech. nology is concerned with "the development, design and operation of information systems, including libraries, indexing and abstracting services and information and data centers" (page 420). Information science, on the other hand, is seen as systems analysis, communication theory; based on linguistics, mathematics, epistemology, psychology, nourophysiology and so on. To describe this whole ficld La Fontaine and Otlet, at the turn of the century, coined the term "documentation", which covers both the craft and the learned aspects. Admittedly much hardware has been added in recent years, but we must not undervalue the craft side.

Perhaps the only way at present of finding out what is intended by "information science and technology" is to equate it pragmatically with the fourteen chapters in which the literature of 1966 is surveyed. These can be considered in two parts-the core (nine chapters) and the periphery (five chapters). The former covers user needs for, and flow patterns of, information; content analysis (classification, indexing and abstracting); design and evaluation of information systems; mechanization in libraries and information centres, both the hardware and the related software; and publication and dissemination of information. Farther away from the centre are autornated language processing, specialized information retrieval in chemistry and medicine, national systems and networks and professional aspects and training. 